\title{
Críticas de Rousseau ao Jus Ad Bellum e ao Jus in Bello de Hugo Grotius ${ }^{1}$ \\ ROUSSEAU'S CRITIQUE OF GROTIUS' JUS AD BELLUM AND JUS IN BELLO
}

Evaldo Becker ${ }^{2}$

\begin{abstract}
RESUMO: Nosso objetivo no presente artigo é apresentar algumas das principais críticas dirigidas por Rousseau às ideias acerca do direito "da" e principalmente "na" guerra, tal como aparecem na obra de Hugo Grotius. Rousseau insiste para que seus leitores não esqueçam "de jeito nenhum" que ele não procura "[...] o que torna a guerra vantajosa àquele que o faz, mas o que a torna legítima." E lembra que "[...] sempre há um custo em ser justo", mas que isso não é motivo para nos dispensarmos de sê-lo. É preciso estabelecer regras que rejam as açốes empreendidas, mesmo no seio dos combates, para que se distingam as guerras das simples pilhagens.
\end{abstract}

PALAVRAS-CHAVE: Rousseau. Grotius. Jus ad bellum. Jus in bello. Justiça.

[...] limitar-me-ei, como sempre fiz, a examinar os estabelecimentos humanos por seus princípios, a corrigir, se for possível, as falsas ideias que nos dão os autores interesseiros; e a fazer ao menos com que a injustiça e a violência náo tomem sem pudor o nome de direito e de equidade. (ROUSSEAU, 2011, p. 154).

Nosso objetivo no presente artigo é apresentar algumas das principais críticas dirigidas por Rousseau às ideias acerca do direito "da" e principalmente "na" guerra, tais como aparecem na obra de Hugo Grotius. Faz-se necessário comentar, nesse sentido, que dentre os autores interesseiros, mencionados por Rousseau na epígrafe, podemos com certeza incluir Hobbes e Grotius. O jurista de Delft é designado no Emílio como uma "criança de má-fé" e em outros momentos como "sofista pago" e "pena servil". Contudo, se é verdade

\footnotetext{
${ }^{1} \mathrm{O}$ presente artigo foi desenvolvido no quadro das atividades do projeto de pesquisa "Rousseau e as Relaçôes Internacionais na Modernidade”, financiado pelos editais FAPITEC/Se/FUNTEC/CNPq $\mathrm{N}^{\circ} 04 / 2011$ (PPP) e Universal - MCTI/CNPq Nº 014/2012.

http://dx.doi.org/10.1590/S0101-317320150004000012

${ }^{2}$ Universidade Federal de Sergipe. E-mail: evaldobecker@gmail.com
} 
que Rousseau critica Grotius, é verdade também, como bem mostra Derathé, em seu Rousseau e a ciência politica de seu tempo, que ele leu e deve muito às teorias do autor holandês. ${ }^{3}$ Postura semelhante é expressa por Simone Goyard-Fabre. Em seu livro La construction de la paix ou le travail de Sisyphe, a autora afirma ser incontestável que "[o] pensamento de Rousseau se nutriu do pensamento de Grotius”, mas que, apesar disso, não é certo que Rousseau o tenha lido bem. E, em uma nota explicativa, ela precisa:

Digamos mais precisamente que Rousseau conhece o Direito da guerra e da paz, provavelmente na tradução de Barbeyrac. Ele ignora manifestamente o Relatório de 1605, o Mare liberum e o De Imperio e deixa totalmente de lado as obras teológicas do pensador holandês. (GOYARD-FABRE, 1994, p. 150).

O fato é que Rousseau leu e foi influenciado pela teoria de Grotius, sobretudo no que concerne ao direito da guerra, embora, após uma leitura minuciosa desse texto, o autor tenha percebido a distância existente entre as suas próprias posiçóes e as do jurista holandês. Aliás, a postura ácida de Rousseau em relação a Grotius não foi uma constante. Em suas obras iniciais, o autor genebrino elogiava e indicava a leitura do jurista. Afinal, Grotius é um dos principais autores do direito internacional e, querendo ou não, há que se admitir que ele teve importante papel na superação do ceticismo em relação às possibilidades de se reduzir a belicosidade no cenário político internacional, promovendo uma tentativa de estabelecer um equilíbrio não conflituoso na política interestatal.4

Já nos prolegômenos de $O$ direito da guerra e da paz, Grotius critica Carnéades por seu ceticismo em relação ao direito, tanto civil quanto das

\footnotetext{
3 "Sabemos que Rousseau se vangloria de defender a verdade, mas ele a defende quase sempre contra alguém. É nesse sentido que ele é um devedor de seus adversários, em particular, dos jurisconsultos. Ainda que todas as suas ideias se sustentem umas às outras, raramente ele às expôs sob uma forma sistemática e por elas mesmas. Ele escreve geralmente sob a influência de suas leituras, e só pensa em reação às teorias de seus predecessores" (DERATHÉ, 2009, p. 118).

${ }^{4}$ Arno Dal Ri Júnior, num excelente texto intitulado Hugo Grotius entre o Jusnaturalismo e Guerra Justa: pelo resgate do conteúdo ético do Direito Internacional, ressalta o importante papel da doutrina grotiana no Direito Internacional: "Pode-se afirmar que o conteúdo ético nas teorias grotianas sobre o Direito Internacional se reflete de modo decisivo quando o autor holandês escreve a favor da manutenção da paz entre as naçóes. Um dos principais traços que caracterizou a obra de Grotius e de toda a Escola do Direito Natural, do qual ele foi um dos fundadores, é esta busca incessante da paz como valor que fundamenta o convívio entre as sociedades humanas. Tratava-se de uma tentativa de conduzir o contexto internacional a um equilíbrio náo conflituoso que servisse de base para organizar as relaçōes entre os Estados" (DAL RI JÚNIOR, 2004, p. 78).
} 
gentes ou internacional, como chamamos hoje. Ele sustenta que não é louco o povo que atente aos direitos comuns a todas as naçóes, e continua afirmando:

Assim como o cidadáo que infringe o direito civil em vista da utilidade presente, destrói o germe que contém seu interesse futuro e o de toda a sua posteridade, assim também o povo violador do direito da natureza e das gentes derruba para sempre os anteparos que protegiam sua própria tranquilidade. (GROTIUS, 2004, p. 44).

O fato é que ninguém confia e se alia, conforme o autor holandês, aos que têm reputação de fazer pouco caso do direito, da justiça e da boa-fé. Nesse sentido, Grotius defende que o direito e a justiça devem ser levados em conta, quando se decide sobre a necessidade ou não das guerras e mesmo nas guerras.

Comentando a posição de Rousseau em relação a Grotius e Pufendorf, exposta no Projeto para a educação de Sainte-Marie, Derathé mostra que, no entender de Rousseau, a leitura desses autores seria necessária justamente para se fazer conhecer "[...] os princípios do bem e do mal, assim como os fundamentos sobre os quais está estabelecida a sociedade da qual ele faz parte" (DERATHÉ, 2009, p. 115). Tal assertiva estava presente no século XVIII e ainda hoje permanece válida. Em um dos poucos livros sobre Grotius escritos em língua portuguesa, Macedo lembra que, após mais de quatrocentos anos de seu nascimento, "Hugo Grócio ainda é estudado por pesquisadores do Direito e das Relaçóes Internacionais em todo o mundo. Seu legado permanece objeto de acirradas controvérsias, ora para enaltecer o autor, ora para desmerecê-lo" (MACEDO, 2006, p. 67).

A postura de Rousseau com relação a Grotius varia ao longo do tempo, e de um admirador este passa a ser um crítico ferrenho das posturas do jurista de Delft. O fato é que nesse texto de 1740, ainda conforme Derathé, apesar de Rousseau conhecer os referidos autores, ele ainda não os havia estudado de perto. ${ }^{5}$ Uma certa condescendência com o valor de Grotius ainda é possível de ser percebida até no Discurso sobre a desigualdade, escrito vários anos mais tarde. Na dedicatória deste, num momento em que retrata a nostalgia em relação à sua infância junto ao pai, Rousseau escreve:

Não posso evitar a mais doce emoção ao lembrar a memória do virtuoso cidadão a quem devo meus dias [...]. Vejo-o ainda, vivendo do trabalho

${ }^{5}$ Cf. Derathé: "Esse texto é de 1740. [...] Nessa data, Rousseau conhece sem dúvida Grotius e Pufendorf, mas ainda não os estudou de perto e, sem deles formar uma opinião pessoal, a nosso ver ele se limita a reproduzir a posição do autor dos Pensamentos sobre a educação" (DERATHÉ, 2009, p. 115). 
de suas mãos e nutrindo sua alma das mais sublimes verdades. Vejo Tácito, Plutarco e Grotius diante dele, confundindo-se com os instrumentos de seu ofício. (ROUSSEAU, 1989, p. 35, grifo meu).

Aqui, Grotius aparece ainda como um dos autores que compreende “sublimes verdades”. Todavia, ainda conforme Derathé (2009, p. 115), “[...] um estudo mais aprofundado" fez com que Rousseau mudasse radicalmente de opinião em relação à Grotius. ${ }^{6}$ Essa mudança na perspectiva de análise ficará evidente nos textos posteriores, tais como o Emílio. A repulsa pelos procedimentos correntes em seu tempo, sobretudo no que concerne às questôes ligadas ao direito da guerra e a violência, evidencia-se igualmente, e de forma enfática, nos textos relativos às Instituiçóes Políticas, tais como o Contrato e os Princípios do Direito da guerra.

Ao final do livro V do Emílio, o autor nos indica contra que tipo de teoria iria se posicionar, em suas Instituiçóes Políticas. É Grotius quem ele nomeia como sendo o seu principal adversário nesse terreno, ao lado de Hobbes, que também é mencionado. $\mathrm{O}$ mesmo é igualado à Hobbes quanto à parcialidade em relação aos tiranos e poderosos. E, no entender do autor do Emílio, "[...] a verdade é que seus princípios são exatamente semelhantes; eles só diferem pela expressão. Diferem também pelo método. Hobbes apoia-se em sofismas, e Grotius, em poetas; tudo o mais lhes é comum" (ROUSSEAU, 1999, p. 647).?

Após examinar as várias espécies de sociedades civis, Rousseau expóe seu desejo de investigar as relaçôes existentes entre elas, "[...] umas grandes, outras pequenas, umas fortes, outras fracas, atacando-se, ofendendo-se, destruindo-se umas às outras, e, nessa ação e reação contínua, fazendo mais

\footnotetext{
6 "Um estudo aprofundado desses autores o fez mudar de opiniáo. Ele experimenta entáo, em relação aos jurisconsultos, a mesma antipatia que nutria pelos 'filósofos' ou pelas 'pessoas da igreja'. Ele denuncia incessantemente sua parcialidade, sua venalidade e sua má-fé. Reprova-os, não somente por terem sempre tomado o partido do forte contra o fraco, mas também por terem sido 'pagos' por essa compostura" (DERATHÉ, 2009, p. 115).

${ }^{7}$ Contudo, apesar da acusaçáo segundo a qual Grotius se apoia apenas em poetas, diferentemente de Hobbes, que se apoiaria em sofismas, o fato é que o próprio jurista holandês, nos prolegômenos do Direito da guerra e da paz, afirma que, para estudar e provar as teses relativas ao Direito natural e das gentes, serve-se "[...] do testemunho dos filósofos, dos historiadores, dos poetas e por fim dos oradores" (GROTIUS, 2004, p. 56). E, mais à frente, ainda nos prolegômenos, escreve: "Os pensamentos dos poetas e oradores não têm tanto peso. Fazemos muitas vezes uso deles não tanto para apoiar neles nossas palavras, mas porque das citaçóes desses autores se tira algum ornamento em proveito do que queremos dizer" (GROTIUS, 2004, p. 60).
} 
miseráveis e custando a vida a mais homens do que se eles tivessem conservado sua primeira liberdade" (ROUSSEAU, 1999, p. 659).

Depois de tratar do Estado misto, no qual nos encontramos, seguindo as leis no interior dos Estados e convivendo com a anomia das relaçóes internacionais, Rousseau se pergunta: não seria justamente "[...] essa associação parcial e imperfeita que produz a tirania e a guerra? E a tirania e a guerra não são os maiores flagelos da humanidade?" (ROUSSEAU, 1999, p. 659).

Passando da análise dos Estados particulares às ligas e confederaçóes que se planejaram para tentar remediar nosso estado de insegurança e para nos garantir contra todo "agressor injusto", Rousseau escreve: "Enfim, colocaremos os verdadeiros princípios do direito da guerra e examinaremos porque Grotius e os demais trataram tão mal do assunto" (1999, p. 660).

É precisamente contra Hobbes e Grotius, autores os quais, segundo ele, para agradar os príncipes e os poderosos, despojam o povo de todas as suas prerrogativas, que se construirá a argumentação de Rousseau tanto no Contrato quanto nos Princípios do direito da guerra. É o que fica evidente nesta passagem do livro II do Contrato Social, na qual lemos:

Grotius, refugiado em França, descontente com sua pátria e desejando agradar a Luís XIII, a quem seu livro é dedicado, nada poupa para despojar os povos de todos os seus direitos e para deles revestir os reis, com a melhor arte possível. (ROUSSEAU, 1962, p. 37).

Ao final do mesmo parágrafo, Rousseau ainda insiste que, na medida em que a verdade não leva à fortuna e que o povo não dá embaixadas, cátedras ou pensóes, não há "incentivos" para que os escritores advoguem em seu interesse. No entender de Rousseau, Grotius, sendo pensionista do rei da França e embaixador da Suécia, escrevia justamente para cortejar seus chefes em detrimento dos interesses populares. Tal ocorre claramente em suas definiçôes de Soberania e de "direitos". Vejamos mais precisamente o teor das críticas rousseaunianas, iniciando pelas referentes ao direito $d a$ guerra.

\section{Direito Da GUERRa (JUS AD BELLUM)}

No que tange ao direito da guerra (jus ad bellum), parece-me que as principais críticas de Rousseau a Grotius se concentram na ideia segundo a qual não se pode impor a soberania sobre outros povos, assim como sobre 
pessoas nascidas livres. Além disso, um princípio fundamental, no entender de Rousseau, parece ser o de que o povo é o soberano e que este pode se rebelar contra um jugo injusto imposto pelos que se dizem governantes. Tais posturas são completamente rechaçadas pelo autor holandês, que, no primeiro livro $D o$ Direito da guerra e da paz, escreve:

Francisco de Vitória ousou dar aos habitantes de uma cidade o direito de mover guerra justa para vingar as injúrias das quais o príncipe náo se preocupa em exigir reparação. Sua opinião, contudo, é com razão rejeitada por outros autores. (GROTIUS, 2004, p. 170).

No entender de Grotius, não há nada que se possa fazer contra os "chefes" dos povos. Estes têm plenos direitos sobre seus súditos e podem governar conforme seus próprios interesses, e não em favor dos governados. ${ }^{8}$ Vejamos:

É preciso refutar primeiramente a opiniáo daqueles que querem que a soberania resida em toda parte e sem exceçáo, no povo, de modo que seja permitido a esse último reprimir e punir os reis todas as vezes que fizerem mau uso do poder. Não há sequer uma só pessoa sábia que não veja quanto esta opiniáo causa males e quantos poderia causar ainda, se penetrasse profundamente nas mentes. (GROTIUS, 2004, p. 177).

O autor do Direito da guerra e da paz avança ainda no sentido de legitimar a sujeição voluntária e irrestrita dos povos aos chefes, sejam eles seus próprios chefes, sejam chefes de outros povos. Aqui, recuperando a famigerada leitura aristotélica de acordo com a qual há homens que nascem para mandar e outros para obedecer, Grotius afirma que o mesmo ocorre com os diversos povos; para alguns deles, é mais natural a subserviência do que o mando e o autogoverno. ${ }^{9}$

Dentre as ideias falsas que oferecem os autores interesseiros ou os "sofistas pagos", podemos citar aquelas concernentes à organização interna de um estado legítimo que Rousseau combatera amplamente, no Contrato

\footnotetext{
8 "A característica principal da soberania, em Grócio, reside no fato de que o seu portador - e o autor náo distingue entre soberania do Estado e soberania da pessoa do rei ou de uma assembleia legislativa - não se encontra vinculado por lei a nenhuma autoridade superior. Em especial, os súditos não podem se defender contra o soberano" (MACEDO, 2006, p. 83).

9 "Acrescente-se a isso como, segundo disse Aristóteles, há homens naturalmente escravos, isto é, nascidos para a escravidâo, de igual modo há povos que lhes é mais natural obedecer do que governar" (GROTIUS, 2002, p. 179).
} 
Social. Após ter negado veementemente, no capítulo IV do livro 1, as teorias de Grotius e de Hobbes acerca da escravidão voluntária, Rousseau enfatizará, no capítulo $\mathrm{V}$ do mesmo livro:

Haverá sempre uma grande diferença entre subjugar uma multidão e reger uma sociedade. Sejam homens isolados, quantos possam ser submetidos sucessivamente a um só, e não verei nisso senão um senhor e escravos, de modo algum considerando-os um povo e seu chefe. (ROUSSEAU, 1962, p. 26).

Não se pode legitimamente forçar homens a formarem um povo ou a se integrarem a outro corpo social já formado. A guerra não pode gerar esse tipo de dever. ${ }^{10}$ Menos legítima ainda será considerada a postura grociana, para a qual o direito de escravidão se estende dos homens cativos na guerra aos seus descendentes. Sendo que todos os homens nascem livres, é impensável, para Rousseau, a ideia segundo a qual o filho de um escravo nasceria escravo ou aquilo que Grotius admite, na seção V do livro II, qual seja, que um pai pode dar seu filho como penhor ou mesmo vendê-lo, se houver necessidade. ${ }^{11}$

Não há nada de "natural” na dominação política; esta se dá com base em convençóes artificiais. Dessa forma, a postura grociana, extraída da obra de Tácito, para quem os povos devem "suportar o luxo e a avareza" daqueles que os governam, da mesma forma que suportam a seca e as enchentes, parece completamente despropositada ao cidadão de Genebra. ${ }^{12}$

É sempre salutar ressaltar que a constituição interna dos Estados está intrinsecamente associada aos problemas decorrentes de suas relaçóes

${ }^{10}$ No capítulo XV do livro III intitulado Consideraçôes sobre a conquista da soberania, após elogiar a bondade e a justiça com relação aos povos ou partes deles, Grotius destaca: "Como outras coisas podem ser adquiridas por uma guerra justa, do mesmo modo se pode adquirir o direito daquele que reina sobre um povo e o direito que o próprio povo tem com relação à soberania” (GROTIUS, 2004, p. 1.315).

${ }^{11} \mathrm{Cf}$. Grotius: "Ainda que o poder paterno seja de tal modo ligado à pessoa e ao caráter de pai que náo pode ser separada e transferida a outro, um pai pode contudo naturalmente e quando a lei civil náo coloca obstáculo algum dar seu filho como penhor e, se houver necessidade, mesmo vendê-lo, a partir do momento em que não tiver outro meio para sustentá-lo" (2004, p. 387).

12 Vejamos a seguinte postura grotiana que confirma a acusação de Rousseau: "Tácito diz de modo primoroso: 'Deveis suportar o luxo e a avareza daqueles que governam como suportais a seca, as enchentes e todos os demais flagelos da natureza. Há sempre vícios, enquanto houver homens, mas o mal não é contínuo e é reparado de tempos em tempos pelo bem'. Segundo Marco Aurélio, os magistrados julgam os privados, os príncipes julgam os magistrados e Deus julga os príncipes" (GROTIUS, 2002, p. 188). 
exteriores. Nesse sentido, conforme explicitam Baschofen e Spector, "[...] o direito da guerra tal como Rousseau o concebe é indissociável dos seus princípios do direito político interno" (BASCHOFEN; SPECTOR, 2008, p. 14). E uma maneira segura de reduzir os problemas decorrentes das relaçóes externas, geralmente belicosas, é uma boa organização interna, na qual todos, inclusive os governantes, estejam submetidos às leis. Afinal, não são raras as vezes em que parcelas interesseiras e corruptas dos governos se servem de ameaças externas para empreender a opressão e a retirada de direitos civis.

Passemos agora ao exame de algumas questóes relativas às críticas de Rousseau a Grotius no que concerne ao direito na guerra.

\section{DiReITO NA GUERRA (JUS IN BELLO)}

Estabelecer um adequado ordenamento político interno, no qual todos, inclusive os governantes, estejam submetidos às leis é um passo fundamental na redução da belicosidade. Porém, não é razão suficiente para o fim das hostilidades, pois, enquanto perdurar o estado de anomia nas relaçóes internacionais, a belicosidade dominará a cena política externa. Existem regras que, inclusive durante a guerra, devem ser seguidas, e violências que jamais serão legítimas.

No que diz respeito às relaçóes entre os Estados, Rousseau explicita que, após ter-se formado a primeira sociedade, segue-se necessariamente a formação de todas as outras, pois, ou os homens passam a fazer parte dela, ou precisarão se unir para resistir e não serem engolidos por esta. "Após ter visto a terra toda cobrir-se de novos Estados, após ter descoberto entre eles uma relaçáo geral que tende à sua destruição mútua", Rousseau se pergunta pela essência do corpo social, a fim de saber "[...] por quais tipos de hostilidades eles podem se atacar e se destruir um ao outro" (2011, p. 163). E, tendo em mente que o princípio da vida do corpo político é o pacto social, uma convençáo estabelecida entre os membros que dele participam, é preciso estabelecer os critérios legítimos que regulam as relaçóes entre esses corpos, mesmo quando estes entram em guerra. É necessário investigar quem pode legitimamente declarar a guerra e o que se pode ou náo fazer no intuito de destruir o Estado inimigo.

Não se pode negar que Grotius teve importante papel na instauração do direito internacional. De fato, ele se esforça para implementar um sistema de juridicização dos conflitos internacionais, tipificando as guerras conforme sua justeza e legalidade. E, ainda hoje, sua tipificação da guerra mista parece 
mais factível do que a teorização rousseauniana. Enquanto Rousseau considera que só pode haver guerra entre Estados, Grotius se esforçava também para compreender e inserir no quadro do direito as guerras particulares e as guerras mistas, ou seja, aquelas que tinham de um lado um Estado e, de outro, particulares. ${ }^{13}$ Ele esforça-se por estabelecer tanto os princípios do direito da guerra (jus ad bellum) quanto os princípios relativos ao direito na guerra (jus in bello), desdobramento das teorias da guerra justa tematizadas por Santo Agostinho e outros, avançando, ademais, no exame da neutralidade dos Estados não envolvidos, garantindo essa possibilidade, o que tende a impedir que as guerras se alastrem tomando maiores dimensóes. ${ }^{14}$

Dentre as violências que devem ser proibidas no seio dos combates, Grotius ressalta o envenenamento. Vejamos:

O direito das gentes aceito, contudo, desde muito tempo, senáo por todos os povos, ao menos pelos mais civilizados, é que não seja permitido matar um inimigo pelo veneno. Esse acordo unânime surgiu da consideração da utilidade comum para impedir que os perigos que começavam a ser frequentes nas guerras não se estendessem demasiado. É crível que essa proibição tenha vindo dos reis, cuja vida é protegida contra as armas mais que a dos outros homens, mas o é menos que a dos outros contra o veneno [...] (GROTIUS, 2004, p. 1.104).

Entretanto, é evidente que, ao tentar limitar as violências, seu foco está sempre na preservação dos reis e jamais na dos povos. Se é verdade que o autor holandês se esmera para levar a noção de lei e de direito para o interior

\footnotetext{
${ }^{13}$ Seria importante examinar a atualidade e a pertinência das definiçôes de guerra mista, propostas por Grotius, haja vista que grande parte dos conflitos atuais não se dão entre Estados e seriam mais bem examinados à luz do conceito de guerra mista. Vejamos: "Na atualidade é, portanto, rara a situação na qual dois Estados enfrentam-se abertamente em um conflito armado, enquanto que é muitíssimo mais frequente a situação na qual a guerra se realiza sem que seja dado esse nome, ou na qual se opóem, em território de um Estado, as autoridades estabelecidas e as suas Forças Armadas a uma parte da população. Não obstante, estes conflitos, que não são abertamente internacionais, podem extravasar as fronteiras do território no qual se desenrolam, por causa dos interesses políticos e das alianças" (SWINARSKI, 1988 apud VISACRO, 2009, p. 273).

${ }^{14}$ Paulo Emílio Vauthier Borges de Macedo, em seu livro Hugo Grócio e o direito: o jurista da guerra e da paz, apresenta o seguinte histórico acerca do conceito de guerra justa: "A tradiçấo da guerra justa nasce como uma doutrina cristá, cujos primeiros escritos remontam a Santo Agostinho. [...] O bispo de Hipona firma a posição oficial da Igreja sobre o assunto. Após alguns acréscimos na doutrina, por homens da Igreja como Isidoro de Sevilha e o papa Nicolau I, a guerra justa não recebeu mais atenção durante a Alta Idade Média. Somente depois de as teses serem condensadas no Decreto gratiano, na metade do XII, o assunto volta a interessar os pensadores. Os canonistas e os teólogos passam a esmiuçar as teses até elas adquirirem a sua formulaçáo clássica em Santo Thomás de Aquino. A doutrina passa, então, a interessar toda a escolástica. Essas obras constituem os primórdios do Direito Internacional" (MACEDO, 2006, p. 87).
} 
dos conflitos, é igualmente verdade que ele admite ainda uma ampla gama de violências que seriam autorizadas pelo dito "direito da guerra".

Vale lembrar que Grotius, em seu Direito da guerra e da paz, apoiado tanto nos autores da antiguidade quanto nas escrituras, afirma que o vencedor tem pleno direito sobre os vencidos, e que todos os tratamentos por ele dispensados são autorizados pelo direito natural, precisando que o direito de maltratar se estende inclusive às crianças e às mulheres dos vencidos. Ele cita passagens do Deuteronômio II, 34 onde se lê que "[...] os hebreus condenaram à morte as mulheres e as crianças dos hesbonitas" e, na sequência, destaca as sagradas palavras do Salmo 137, 9, as quais sustentam que "[...] será feliz aquele que esmagar contra as pedras os filhos dos babilônios" (GROTIUS, 2004 , v. 2, p. 1.098).

Tal postura será duramente combatida pelo filósofo genebrino, que escreverá: "Não há nada, diz Grotius, que não se possa impunemente fazer sofrer a tais escravos". Mas, em seu entender, "[...] mesmo que mil povos ferozes tivessem massacrado seus prisioneiros", nada disso teria a ver com a justiça. Isso tem a ver com a realidade dos fatos. Nesse sentido, náo se deve investigar o que se fez, mas o que se deve fazer. Para tanto, é fundamental que se rejeitem as posturas das "vis e mercenárias autoridades", dos doutores que só se preocupam em tornar os homens "[...] escravos, malvados e infelizes" (ROUSSEAU, 2011, p. 168).

Outra norma relativa ao direito na guerra é a célebre questão da manutenção ou não da palavra dada ao inimigo. Grotius salienta que "[...] aquele que prometeu sob a pressáo de um temor injusto poderá ser obrigado, se juntou à promessa a fé do juramento" (GROTIUS, 2004, L. III, p. 1.362)..$^{15}$ Para Rousseau, de forma semelhante ao que ocorre em Maquiavel, pode-se quebrar a palavra dada, quando esta tiver sido extorquida pela força ${ }^{16}$. Nos Fragmentos sobre a guerra, ele insiste que "[...] o juramento anterior que nos

\footnotetext{
${ }^{15}$ Sobre a manutenção da palavra dada, ver Grotius, L. III, cap. XIX. Ele cita Agostinho: "Quando a palavra é dada, deve ser mantida mesmo para com um inimigo a quem se move guerra" (GROTIUS, 2004 , p. $1.358, \$ 4)$. O fato de que a promessa foi extorquida pelo temor não se constitui em obstáculo, se a violência não foi feita àquele que prometeu. "Para que aquele a quem foi prometida alguma coisa seja obrigado a liberar o prometente, é necessário que tenha ele próprio dado ocasiáo a essa promessa por um temor injusto" (GROTIUS, 2004, p. 1.362).

16 "Eu poderia colocar em questẫo se as promessas arrancadas pela força e para evitar a morte são obrigatórias no estado de liberdade, e se todas aquelas que o prisioneiro faz a seu mestre neste estado podem significar outra coisa do que isto. Eu prometo obedecer-lhe por todo o tempo em que sendo mais forte vós não atentares contra a minha vida” (ROUSSEAU, 2011, p. 167).
} 
liga à pátria anula" aquele que nos "submete a um outro soberano visto que o primeiro foi contratado em plena liberdade e o segundo a ferros" (ROUSSEAU, 2011, p. 169).

Dado que, para Rousseau, não se pode, legitimamente, interferir na liberdade dos outros por meio de guerras de conquista, as ameaças extorquidas não possuem qualquer legitimidade. Conforme o autor genebrino, existe uma prevalência das promessas feitas livremente sobre aquelas obtidas por meio de ameaças. Ele pergunta se são as promessas "[...] feitas com a pátria em plena liberdade ou aquelas que o terror da morte nos fará contratar com o inimigo vencedor" que devem prevalecer. ${ }^{17}$ Criticando Grotius, ele questiona o pretenso direito sobre os prisioneiros assujeitados e deixa claro que os juramentos feitos livremente com a pátria têm prevalência sobre aqueles que o inimigo arranca de nossa fraqueza (ROUSSEAU, 2011, p. 168).

Rousseau insiste para que seus leitores não esqueçam "de jeito nenhum" que ele não procura "[...] o que torna a guerra vantajosa àquele que o faz, mas o que a torna legítima." E lembra que "sempre há um custo em ser justo", mas que isso não é motivo para nos dispensarmos de sê-lo (2011, p. 165). É preciso estabelecer regras que rejam as açōes empreendidas, mesmo no seio dos combates, para que se distingam as guerras das simples pilhagens. Comuns em seu tempo, e talvez mais ainda no nosso, são os combates que têm por finalidade última - independentemente das justificativas públicas apresentadas - apenas a pilhagem de recursos necessários ao invasor, sejam eles bem alimentícios e ouro, sejam, como atualmente, o petróleo ou os diamantes. Nesse sentido, denunciando a baixa avidez e a cobiça que são os verdadeiros móveis das "guerras", Rousseau afirma:

A terra, o dinheiro, os homens e todos os despojos de que se pode apropriarse se tornam assim os principais objetivos das hostilidades recíprocas, e esta baixa avidez, mudando insensivelmente as ideias das coisas, a guerra, enfim, degenera em pilhagem, e de inimigos e guerreiros tornamo-nos pouco a pouco tiranos e ladrôes. (ROUSSEAU, 2011, p. 165).

O que importa para Rousseau é pensar os corpos políticos em termos de legitimidade, e náo se deixar impregnar pelas teorias que, em seu entender, pretendem apenas legitimar os fatos que a história de violência e opressão descreve em abundância. "Definitivamente, estima Rousseau, se Grotius tem

${ }^{17}$ Cf. ROUSSEAU (2011, p. 167-168). 
razão em fazer da guerra um problema de direito, ele comete o mesmo erro que Hobbes: ele não sabe tratar o fato pelo direito" (GOYARD-FABRE, 1994, p. 152). A mesma compreensão é expressa por Derathé. Segundo este, o que Rousseau denuncia em Grotius “[...] é, em primeiro lugar, seu método”. Grotius advoga uma causa ruim, ele se serve do método "[...] que os juristas empregam de ordinário quando tratam do direito positivo. É a história que ele pretende tirar a força de sua argumentação e, por mais que avance, ele se exaure, provando-a com exemplos ou fatos históricos" (DERATHÉ, 2009, p. 119-120)..$^{18}$

Contudo, a história não possui prevalência sobre a essência dos corpos políticos. Ao menos não em termos de legitimidade. Assim, não importa a Rousseau se o desregramento, os excessos de todos os tipos e as violências incontáveis sempre pautaram as relaçôes internacionais. Essas relaçôes de pilhagem e desrespeito jamais poderão se alçar à categoria de açóes legítimas, permanecerão presas ao âmbito dos fatos, dos preconceitos. Tais açóes estão irremediavelmente no campo das injustiças.

BECKER, Evaldo. Rousseau's critique of Grotius' Jus ad bellum and Jus in bello. Trans/ Form/Ação, Marília, v. 38, p. 139-152, 2015. Edição Especial.

\begin{abstract}
This paper presents some of Rousseau's main criticisms of the right "of" and, principally, "in" war, as they appear in the works of Hugo Grotius. Rousseau asks his readers not to forget, "by any means", that he doesn't seek to discover "[...] what makes war advantageous to those who make it, but what makes it legitimate". He also reminds us that "[...] there is always a cost to being fair", but that this is not a reason for us to give up being so. It is necessary to establish rules for actions undertaken, even in the middle of combat, in order to distinguish war from mere pillaging.
\end{abstract}

KEYWORDS: Rousseau. Grotius. Jus ad bellum. Jus in bello. Justice.

\title{
REFERÊNCIAS
}

BASCHOFEN, Blaise; SPECTOR, Céline. Introduction. In: (Dirs.). Principes du droit de la guerre: écrits sur la paix perpétuelle. Edition nouvelle et présentation de l'établissement des textes par Bruno Bernardi et Gabriella Silvestrini. Textes commentés par

18 "O próprio Grotius, em seu discurso preliminar, explicou-se acerca da importância que confere à História e do uso que dela se deve fazer." (DERATHÉ, 2009, p. 120). Vejamos: Prolegômenos, \$46: "A história tem uma dupla utilidade para nosso tema. Ela fornece exemplos e apreciações. Os exemplos têm tanto mais autoridade porque são extraídos dos melhores tempos e dos melhores povos. Por isso preferimos os antigos exemplos dos gregos e dos romanos aos outros" (GROTIUS, 2004, v. 1, p. 60). 
B. Bascofen, B. Bernardi, F. Guénard et C. Spector avec la collaboration de G. Lepan et . G. Waterlot. Paris: J. Vrin, 2008.

BECKER, Evaldo. Rousseau e as relaçôes internacionais na modernidade. Cadernos de Ética e Filosofia Política da USP, São Paulo: n.16, p. 13-32, 2010.

DAL RI JÚNIOR, Arno. Hugo Grotius entre o Jusnaturalismo e guerra justa: pelo resgate do conteúdo ético do direito internacional. In: MENEZES, Wagner (Org.). O direito internacional e o direito brasileiro: homenagem a José Francisco Rezek. Ijuí: Ed. Unijuí, 2004.

DERATHÉ, Robert. Jean-Jacques Rousseau e a ciência política de seu tempo. Tradução de Natalia Maruyama. São Paulo: Barcarolla : Discurso Editorial, 2009.

GOYARD-FABRE, S. La construction de la paix: ou le travail de Sisyphe. Paris: Vrin, 1994.

. La guerre et le droit international dans la philosophie de Rousseau. Études Jean Jacques Rousseau, n. 7, 1995.

GROTIUS, Hugo. O direito da guerra e da paz. Tradução de Ciro Mioranza. 2. ed. Ijuí: Ed. Unijuí, 2004. 2 v. (Coleção Clássicos do Direito Internacional).

. Le droit de la guerre et de la paix. Édité par D. Alland et S. Goyard-Fabre. Traduit par P. Pradier-Fodéré. Paris: P.U.F, 1999.

MACEDO, Paulo Emílio Vauthier Borges de. Hugo Grócio e o Direito: o jurista da guerra e da paz. Rio de Janeiro: Lumen Juris, 2006.

ROUSSEAU, J. J. Do Contrato social. In: - Obras J.-J. Rousseau. Introduçóes e Notas de Paul Arbousse-Bastide e Lourival Gomes Machado. Tradução de Lourdes Santos Machado. São Paulo: Globo, 1962. v. 2.

. Oeuvres complètes. Paris: Gallimard, 1959-1995. 5v.

. Emílio ou da educação. Tradução Roberto Leal Ferreira. 2. ed. São Paulo: Martins Fontes, 1999.

. Princípios do direito da guerra. Tradução de Evaldo Becker. Revisão da tradução de Ricardo Monteagudo. Trans/Form/Ação, Marília, v. 34, p. 149- 172, 2011.

VISACRO, Alessandro. Guerra irregular: terrorismo, guerrilha e movimentos de resistência ao longo da história. São Paulo: Contexto, 2009.

Recebido / Received: 15/04/2015

Aprovado / Approved: 24/06/2015 
BECKER, E. 